\title{
Effective Recovery Process of Copper from Waste Printed Circuit Boards Utilizing Recycling of Leachate
}

\author{
JOONA RAJAHALME @ị, ${ }^{1,2}$ SIIRI PERÄMÄKI, ${ }^{1,3}$ ROSHAN BUDHATHOKI, ${ }^{1}$ \\ and ARI VÄISÄNEN ${ }^{1,4}$ \\ 1.-Department of Chemistry, Chemistry in Circular Economy, University of Jyväskylä, P.O.

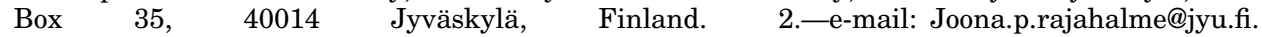 \\ 3.—e-mail: Siiri.e.peramaki@jyu.fi. 4.—e-mail: Ari.o.vaisanen@jyu.fi
}

This study presents an optimized leaching and electrowinning process for the recovery of copper from waste printed circuit boards including studies of chemical consumption and recirculation of leachate. Optimization of leaching was performed using response surface methodology in diluted sulfuric acid and hydrogen peroxide media. Optimum leaching conditions for copper were found by using $3.6 \mathrm{~mol} \mathrm{~L}{ }^{-1}$ sulfuric acid, 6 vol.\% hydrogen peroxide, pulp density of $75 \mathrm{~g} \mathrm{~L}^{-1}$ with 186 min leaching time at $20^{\circ} \mathrm{C}$ resulting in complete leaching of copper followed by over $92 \%$ recovery and purity of $99.9 \%$ in the electrowinning. Study of chemical consumption showed total decomposition of hydrogen peroxide during leaching, while changes in sulfuric acid concentration were minor. During recirculation of the leachate with up to 5 cycles, copper recovery and product purity remained at high levels while acid consumption was reduced by $60 \%$.

\section{INTRODUCTION}

The revolution of information technology has led to rapidly increasing generation of waste electrical and electronic equipment (WEEE), with the annual global production of approximately 45 million metric tons in 2016. The production of WEEE has been estimated to reach 52 million metric tons in $2021 .^{1}$ The European Union has undertaken this problem by setting directives on $\mathrm{WEEE}^{2}$ and the Restriction of Hazardous Substances, ${ }^{3}$ aiming at proper management and reduction of WEEE. However, WEEE is also a valuable secondary resource containing base and precious metals, with high economic prospects, but the heterogeneity of the material generates great challenges in waste treatment processes as well as in the recovery of metals. Printed circuit boards (PCBs) are the most valuable fraction of WEEE containing high concentrations of base metals, including up to 27 wt.\% of copper, but also high concentrations of precious metals including silver, gold, and palladium. ${ }^{4}$

(Received August 13, 2020; accepted November 23, 2020; published online December 21, 2020)
Pretreatment is often required to increase the efficiency of metal recovery by separating metallic and non-metallic fraction, e.g., ceramics and plastics. ${ }^{4}$ Commonly used pretreatment methods for PCBs are various physical, ${ }^{5-7}$ thermal, ${ }^{8,9}$ and chemical treatments, ${ }^{10,11}$ of which a combination can also be employed. Pretreated PCB material, with fine particle size $(500-1000 \mu \mathrm{m})$, is commonly used for the leaching studies of metals. ${ }^{12-16}$

Diluted mineral acids and mixtures of them have been studied widely for leaching of the copper, ${ }^{8,12,13,16-22}$ while bioleaching ${ }^{23-25}$ and salt solutions at various $\mathrm{pH}^{26-28}$ have also been used. Oxidation capability of sulfuric acid is decreased when an acid is diluted, and therefore the copper leaching capacity of diluted sulfuric acid is limited. However, addition of an oxidizing agent (e.g., hydrogen peroxide) can be used to increase the leaching efficiency of copper from the PCBs. The effects of hydrogen peroxide and sulfuric acid concentration, as well as pulp density, leaching temperature, and time, on copper recovery from PCBs have been studied previously. ${ }^{16,21,29-31}$ However, the combined effect of these parameters to the leaching efficiency of copper has been rarely studied, ${ }^{16}$ and previous optimizations have not taken 
into account the possible two-way interactions of variables, which can be found by using response surface methodology (RSM). In addition, chemical consumption of sulfuric acid leaching with hydrogen peroxide has not been studied in detail before.

Once copper has been leached, various techniques can be used for recovery from sulfuric acid and hydrogen peroxide leaching solution of PCBs, including electrowinning, ${ }^{14,32}$ solvent extraction and precipitation, ${ }^{27}$ and crystallization. ${ }^{16}$ Electrowinning is a widely used technique in industrial processes for the recovery and purification of high concentrations of copper from sulfuric acid media. The addition of chemicals is not needed in the electrowinning, unlike in other conventional recovery techniques, which decreases chemical consumption of the copper recovery. Recycling of the sulfuric acid solution after recovery process has rarely been studied, ${ }^{16}$ even though it has an important role for understanding the possibility of sulfuric acid recycling in the copper recovery process.

Optimization of sulfuric acid and hydrogen peroxide leaching for copper was carried out with RSM, for five parameters, from pretreated PCBs. After the leaching and filtration, the copper was recovered from the leachate using electrowinning with a constant current density. Consumption of hydrogen peroxide and sulfuric acid was studied in both leaching and electrowinning steps to estimate the recirculation potential of leachate and therefore reduce chemical consumption of copper recovery. In the final stage, a recirculation experiment of leachate was performed, with 5 cycles to estimate the chemical consumption as well as the recovery and purity of the obtained copper product.

\section{MATERIALS AND METHODS}

\section{Pretreatment and Elemental Analysis of Waste PCBs}

The waste PCBs were received from a local waste treatment company, specializing in the collection, dismantling, and physical pretreatment of WEEE. The material had been ground to $6 \mathrm{~mm}$ size after manual disassembly from electronic equipment. The material was first thermally treated at $300 \mathrm{C}$ for $30 \mathrm{~min}$ followed by at $950^{\circ} \mathrm{C}$ for $120 \mathrm{~min}(\mathrm{CWF} 1300$; Carbolite, UK) followed by grinding with a ball mill (S1000; Retsch, Germany) and sieving (Retsch). Detected mass loss was 32 wt.\% in thermal treatment and, eventually, after grinding and sieving, $40 \mathrm{wt} . \%$ of the initial mass remained with particle size $<0.5 \mathrm{~mm}$. The sieved fraction $<0.5 \mathrm{~mm}$ was selected as the sample due to sufficient homogeneity.

The pretreated PCB material was dissolved using aqua regia [nitric acid (67\%; puriss p.a.; Sigma Aldrich) and hydrochloric acid (37\%; puriss p.a.; Sigma Aldrich)] in a microwave oven (Mars 6 iWave; CEM, USA) for the analysis of elemental concentrations. Concentrations of $\mathrm{Cu}, \mathrm{Ag}, \mathrm{Al}, \mathrm{Au}, \mathrm{Fe}, \mathrm{Pb}$,
$\mathrm{Pd}, \mathrm{Pt}$, and $\mathrm{Zn}$ were analyzed from diluted microwave digested samples using ICP-OES (Optima 8300; PerkinElmer, USA). More detailed information about the microwave digestion is presented in supplementary information and the ICP-OES measurements in Tables S.I and S.II.

Relative standard deviations (RSDs) of sample replicates were followed in the analysis, and RSD values exceeding $5 \%$ have been expressed in the results tables.

\section{Optimization of Copper Leaching}

A face-centered central composite design consisting of 36 experimental runs, including 10 repeats of the central points, was created using RcmdrPlugin.DoE (v.0.12-3) 33,34 in an R software environment. ${ }^{35}$ Due to the heterogeneity of the PCB sample material, the number of center points was set higher than usual, at 10, to minimize the error of the RSM. The $\mathrm{R}$ software randomized the leaching sequence of the samples to prevent systematic errors. The effects of sulfuric acid concentration, hydrogen peroxide concentration, pulp density, leaching time, and temperature on copper leaching efficiency were studied at three levels. Table I represents the experimental domain of interest. Selected levels were based on results from preliminary experiments as well as from Yang et al. and Birloaga et al. ${ }^{16,36}$

Leaching experiments, based on the central composite design, were carried out using the pretreated PCB material. A sample of $3 \mathrm{~g}$ was leached with 17 , 24 , or $40 \mathrm{~mL}$ of leachate in the designed leaching conditions (Table S.III) using sulfuric acid (95-97\%) and hydrogen peroxide (30\%; AnalaR NORMAPUR; VWR Chemicals). The mass of the samples was kept constant to minimize variation of analyte concentrations due to heterogeneity of the sample material. Leaching experiments were performed in a 100-mL Erlenmeyer flask covered with a lid, with magnet bar stirring. Temperature control was carried out with a water bath and a thermometer. The leachate was filtrated (Whatman 41 filter paper) and diluted with ultrapure water (resistivity of $18.5 \mathrm{M} \Omega \mathrm{cm}$; Purelab Ultra; Elga, UK before elemental analysis using ICP-OES. Leaching efficiencies were calculated comparing the leaching

Table I. Used variables, codes of variables, and levels of variables in the experiment

\begin{tabular}{lcrrrr}
\hline & & & \multicolumn{3}{c}{ Levels } \\
\cline { 3 - 6 } Variable & & & $-\mathbf{1}$ & $\mathbf{0}$ & $\mathbf{1}$ \\
\hline $\mathrm{H}_{2} \mathrm{O}_{2}$, vol.\% & $\mathrm{H}_{2} \mathrm{O}_{2}$ & & 0 & 3 & 6 \\
Acid concentration, mol L & $\mathrm{AC}$ & 1 & 3 & 5 \\
Pulp density, g L & $\mathrm{PD}$ & 75 & 125 & 175 \\
Time, h & $\mathrm{Pime}$ & 1 & 5 & 9 \\
Temperature, ${ }^{\circ} \mathrm{C}$ & Temp & 20 & 40 & 60 \\
\hline
\end{tabular}


concentrations to the metal concentrations of aqua regia digestion.

Fit of the model and experimental data were estimated with regression of the model and a lackof-fit test. The significance of the variables was analyzed based on $\operatorname{Pr}(>|t|)$ values, and a single term was defined as significant to the RSM if the $\operatorname{Pr}(>|t|)$ value was lower than the significance level of $\alpha|=| 0.05 \mid$. Correspondence between the model and the experimental results was confirmed with leaching experiments, with a sample mass of $3 \mathrm{~g}$, using optimum conditions predicted by the model in Table III (below).

\section{Chemical Consumption in the Copper Recovery Process}

Pretreated PCBs, with sample mass of $11.25 \mathrm{~g}$ and leachate volume of $150 \mathrm{~mL}$, were leached in optimized leaching conditions (a) presented in Table III (below). Leaching and filtration were performed similarly as in Sect. 2.2. Electrowinning experiments were performed with $115 \mathrm{~mL}$ of leachate with a current density of $0.04 \mathrm{~A} \mathrm{~cm}^{-2} 32$ using SBS EG-1 (S.B.S Instruments) electrolysis apparatus with a circular platinum gauze electrode as the working electrode, and a platinum spiral electrode as the counter electrode. The distance between the electrodes was approximately $1.5 \mathrm{~cm}$. Copper(II) reduction is the main reaction, with the cell potential of $-0.8871 \mathrm{~V}$ in electrowinning, ${ }^{37}$ and possible secondary reactions are shown in SI. Electrowinning was stopped when a sudden increase in cell voltage was observed, indicating that all the copper had been reduced to the gauze electrode.

Sampling was carried out before, every $45 \mathrm{~min}$, and after the leaching and electrowinning steps. Samples were analyzed by ICP-OES, acid-base, and potassium permanganate titration, ${ }^{26,38}$ to analyze the metals, sulfuric acid, and hydrogen peroxide concentrations, respectively. However, the hydrogen peroxide concentration was not analyzed from the electrowinning samples due to decomposition in the leaching step. More detailed information on both titrations is shown in SI.

After electrowinning, the working electrode was leached with $100 \mathrm{~mL}$ of $10.0 \%$ nitric acid (67\%) to analyze the purity of the electrolyzed copper. All the samples were analyzed for elemental concentrations using ICP-OES.

\section{Recirculation Experiment}

Recyclability of the leaching agents was studied with five sequential recovery cycles, as described in Sect. 2.3, using a fresh PCB sample in each leaching step. Leachate volume of $150 \mathrm{~mL}$, with $75 \mathrm{~g} \mathrm{~L}^{-1}$ pulp density, was used in each cycle. Before the leaching step in each cycle, $30 \mathrm{~mL}$ of hydrogen peroxide and $7.4 \mathrm{~mL}$ of concentrated sulfuric acid were added into the circulated leachate. This was done to compensate for decomposition of the hydrogen peroxide and dilution of the sulfuric acid caused by the hydrogen peroxide addition. In the 2nd cycle, $15 \mathrm{~mL}$ of fresh $3.5 \mathrm{~mol} \mathrm{~L}^{-1}$ sulfuric acid was needed to add due to a higher loss in the filtration step. Electrowinning was performed for the leachate with the volume of $125 \mathrm{~mL}$, due to losses in sampling and filtration, with a current density of $0.04 \mathrm{~A} \mathrm{~cm}^{-2}$ until a sudden increase in cell voltage was observed. Sampling was carried out before and after each leaching and electrowinning step and the samples were analyzed similarly as in the Sect. 2.3. Yields of leaching were calculated similarly as in Sect. 2.2, but the initial concentrations of leachate were subtracted before calculation. Recovery of electrowinning was calculated by comparing the final concentration to the initial concentration.

\section{RESULTS AND DISCUSSION}

\section{Elemental Concentrations in the Waste PCBs}

The pretreated waste PCB material was found to contain $18.6 \mathrm{wt} . \%$ of copper as the major component, while aluminum, zinc, and iron were also present in high quantities, as shown in Table II. In terms of precious metals, silver and gold were found in the PCB material. In previous publications, copper concentrations have varied from 8 wt.\% to 43 wt. $\%$, when the particle size of mainly $<1.0 \mathrm{~mm}$ has been studied. ${ }^{16,21,29,31,36,39}$ The waste PCB material utilized here with a particle size of $<0.5$ $\mathrm{mm}$ was found to possess rather average copper content if compared to previous publications. Havlik et al. studied the combustion of printed circuit boards and found that metallic copper was oxidized to $\mathrm{CuO}$ at $900^{\circ} \mathrm{C} .{ }^{8}$ Simulation with the HSC Chemistry 9 (Outotec, v.9.9.2.3) stability diagram tool, also estimated that copper was oxidized to $\mathrm{CuO}$ during thermal treatment at atmospheric pressure. A predominance phase diagram of simulation for copper is shown in Fig S.1 in SI.

\section{Analysis of the Response Surface Model (RSM)}

The sequence of the experimental runs, including the measured extraction of copper (\%) as responses of the data points, are shown in Table S.III. The extraction of copper varied from 52\% to $95 \%$ within the experimental domain. From the results, a RSM in Eq. 1 was formed:

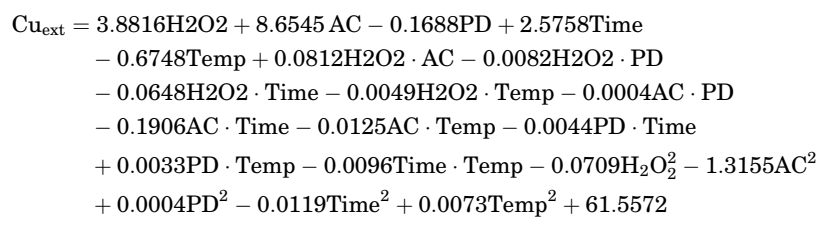

The ANOVA table of the RSM is presented in Table S.IV. Two-tailed $F$ tests of the model, with a level of confidence of $95 \%$, demonstrated a non- 
Table II. Average elemental concentrations $\left(\mathrm{mg} \mathrm{kg}^{-1}\right)$ in the pretreated waste PCB material

\begin{tabular}{|c|c|c|c|c|c|c|c|c|c|}
\hline Element & Ag & $\mathbf{A l}$ & $\mathbf{A u}$ & $\mathbf{C u}$ & $\mathbf{F e}$ & $\mathbf{P b}$ & Pd & $\mathbf{P t}$ & $\mathbf{Z n}$ \\
\hline Sample, $\mathrm{mg} \mathrm{kg}^{-1}$ & 2590 & 48,700 & $290^{\mathrm{a}}$ & 186,000 & 27,300 & 8700 & $<\mathrm{LOD}$ & $<\mathrm{LOD}$ & 29,900 \\
\hline
\end{tabular}

$<L O D=$ measured concentration below limit of detection. ${ }^{\mathrm{a}} \mathrm{RSD}>10 \%$.

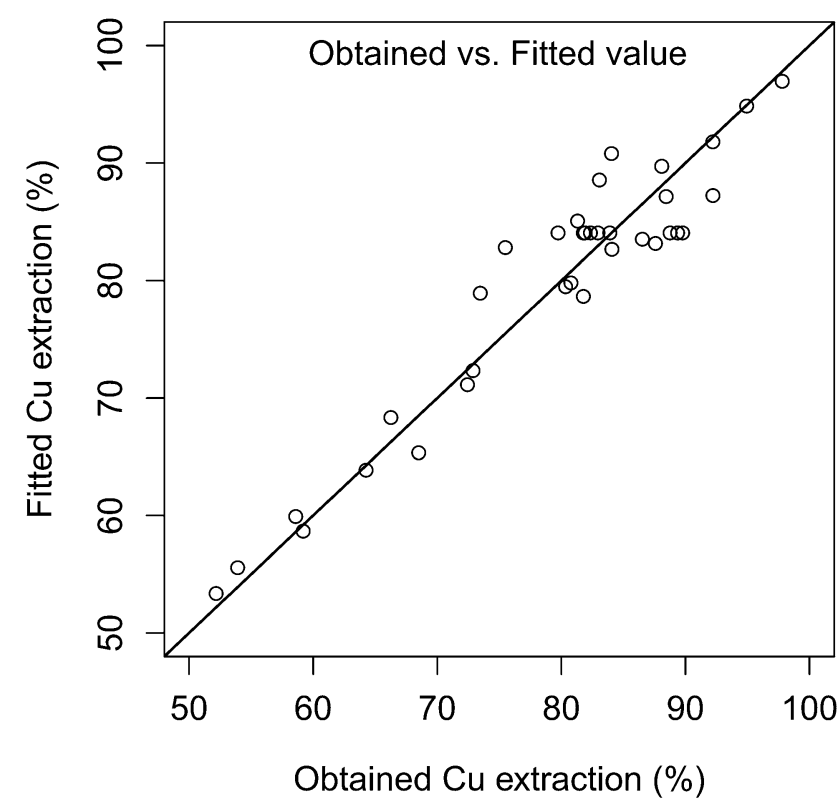

Fig. 1. Comparison plot between the obtained and the RSM-fitted extraction efficiencies (\%) of copper.

significant lack-of-fit $\left(3.069<F_{6,9}=4.320\right)$ and a significant regression of the model $\left(7.604>F_{20,15}=2.756\right)$, indicating good agreement with the experimental data. ${ }^{40,41}$ The correlation coefficient $\left(R^{2}\right)$ of the model was high at 0.910 , and the adjusted $R^{2}$ was at an acceptable level of 0.791 . The slightly lower adjusted $R^{2}$ value is typical for cases with a high number of variables and nonsignificant terms in the model ${ }^{42}$ High values of correlation coefficients indicate the lack of systematic error in the model. The copper extraction yields estimated by Eq. 1 compared well with the experimentally obtained values, as seen in Fig. 1. This indicates good predictability of the RSM employed in this study.

The effects of linear, quadratic, and two-way interactions on the leaching efficiency of copper are shown in Table S.V in SI. The linear effect of $\mathrm{H}_{2} \mathrm{O}_{2}$ vol.\% was found significant at $\alpha|=| 0.001 \mid$. Meanwhile, significant two-way interactions were observed only between $\mathrm{H}_{2} \mathrm{O}_{2}$ vol.\% and pulp density with $\alpha|=| 0.01 \mid$, and pulp density and leaching temperature with $\alpha|=| 0.05 \mid$. The quadratic effect of each variable was not significant at $\alpha|=| 0.05 \mathrm{I}$.
The other terms of the model were found to have non-significant effects on the RSM. Graphical presentations of the response surfaces A-J are shown in Fig. 2. Clear effects of hydrogen peroxide vol.\% and pulp density were detected from the surfaces.

Leaching conditions resulting in the optimum extraction of copper were numerically calculated from Eq. 1. Calculated conditions and responses are shown in Table III. Both calculated conditions resulted in over $99.5 \%$ extraction for copper. Values of $\mathrm{H}_{2} \mathrm{O}_{2}$ vol.\%, acid concentration, and pulp density were the same in both calculated conditions; only leaching time and temperature changed between the calculated optimum conditions. The validity of the optimum conditions predicted by the RSM in Table III, was confirmed with leaching experiments using both leaching conditions. The RSM precisely predicted the extraction of copper at the optimum conditions with less than $4 \%$ difference in comparison to the experimental data. According to a paired $t$ test (using Table S.VII values), statistically significant differences were not observed between the two leaching conditions for the leaching efficiency of copper.

Copper was leached effectively with $96 \%$ and $101 \%$ efficiencies in both optimum conditions, as can be seen from Table III. Copper leaching efficiency of over $100 \%$ was observed due to normal analytical uncertainty in the elemental analyses. Roughly $30 \%$ of aluminum and iron and over 50\% of zinc was dissolved in leaching condition (a) and the increase in temperature increased the leaching rate of these elements. However, lead and the precious metals were not dissolved or dissolved only in trace concentrations in either conditions. More detailed information of other metal leaching efficiencies in optimum conditions is shown in Table S.VI in SI.

In the present study, optimum concentrations of leachate were $3.6 \mathrm{~mol} \mathrm{~L}^{-1}$ of sulfuric acid and 6 vol.\% of hydrogen peroxide, while in previous literature, the optimum concentration of sulfuric acid has been found to be between $0.3 \mathrm{~mol} \mathrm{~L}^{-1}$ and $4.3 \mathrm{~mol} \mathrm{~L}^{-1}$, and hydrogen peroxide between 0.6 and 14.7 vol.\%. ${ }^{16,21,29,31,36,39}$ Previous results for leaching temperature and time have varied widely, between room temperature and $80^{\circ} \mathrm{C}$, and leaching times of 3-18 h. This study demonstrates the possibility of using either a shorter leaching time with elevated temperature $\left(1 \mathrm{~h}, 60^{\circ} \mathrm{C}\right)$, or a longer 
(a)

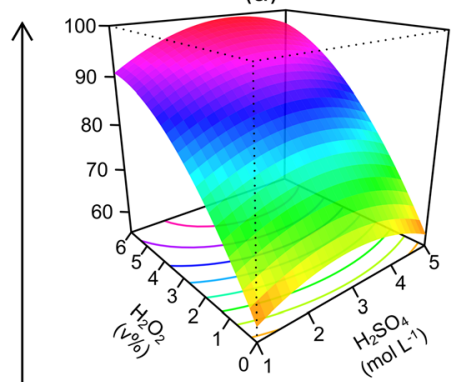

(e)

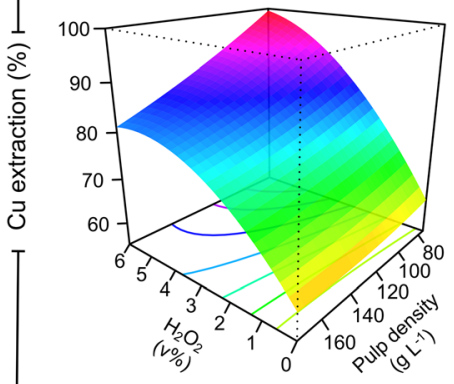

(b)

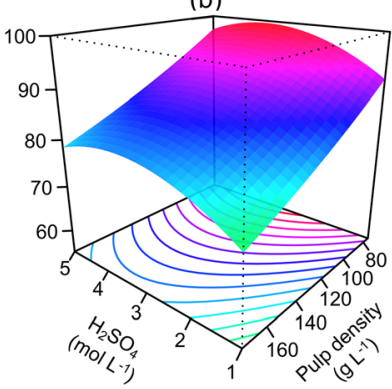

(f)

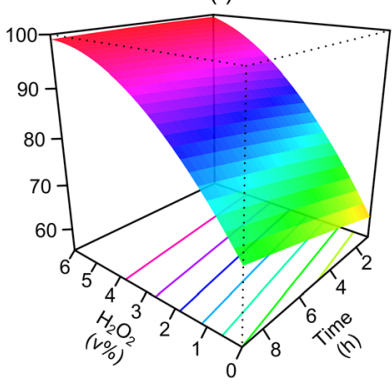

(i)

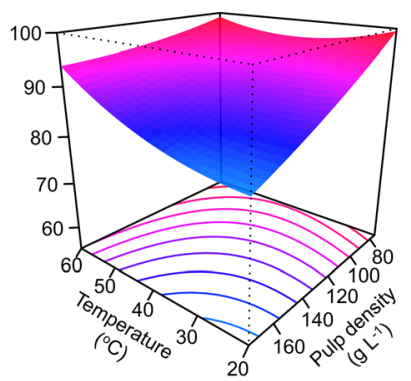

(c)

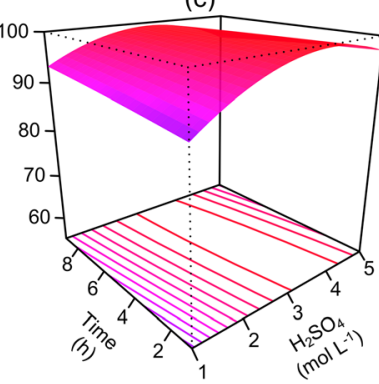

(g)

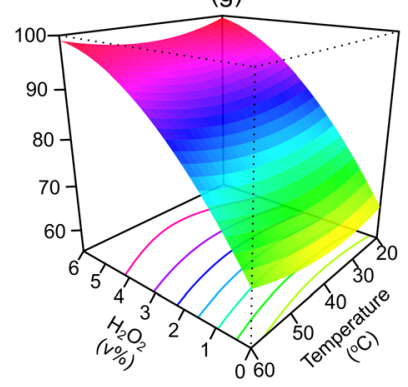

(j)

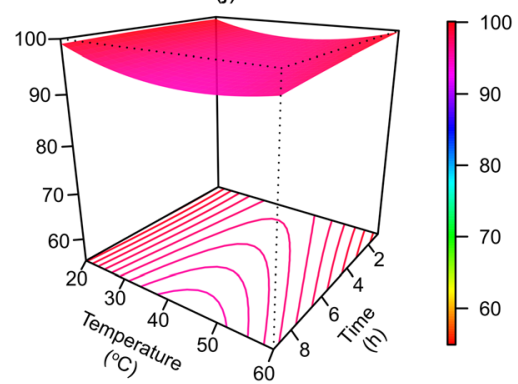

Fig. 2. Response surfaces of copper leaching. Effect of variables: (a) hydrogen peroxide vol.\% and sulfuric acid concentration, (b) sulfuric acid concentration and pulp density, (c) leaching time and sulfuric acid concentration, (d) leaching temperature and sulfuric acid concentration, (e) hydrogen peroxide vol.\% and pulp density, (f) hydrogen peroxide vol.\% and leaching time, (g) hydrogen peroxide vol.\% and leaching temperature, (h) leaching time and pulp density, (i) leaching temperature and pulp density, and (j) leaching temperature and time. The rest of the variables were kept at constant values at the presented surfaces: $\mathrm{H}_{2} \mathrm{O}_{2} 6.00$ vol. $\%$, sulfuric acid concentration 3.58 mol $\mathrm{L}^{-1}$, pulp density $75.00 \mathrm{~g}$ $\mathrm{L}^{-1}$, leaching time $3 \mathrm{~h} 6 \mathrm{~min}$, and temperature $20^{\circ} \mathrm{C}$.

Table III. Calculated optimum conditions, calculated extractions of copper, and experimental extractions of copper

\section{Variable}

$\mathrm{H}_{2} \mathrm{O}_{2}$, vol. $\%$

Acid concentration, mol L $\mathrm{L}^{-1}$

Pulp density, $\mathrm{g} \mathrm{L}^{-1}$

Time

Temperature, ${ }^{\circ} \mathrm{C}$

Calculated extraction of copper, $\%$

Experimental extraction of copper, \%

\section{Leaching condition, a}

6.00

3.58

75.00

$3 \mathrm{~h} 6 \mathrm{~min}$

20.00

99.54

101.0
Leaching condition, $b$

6.00

3.54

75.00

$1 \mathrm{~h}$

60.00

99.78

96.3 leaching time at room temperature $(3 \mathrm{~h} 6 \mathrm{~min}$, $20^{\circ} \mathrm{C}$ ). Both conditions result in $>96 \%$ recoveries in the leaching of copper. Pulp density has also been used with a large variation range, but commonly approximately $100 \mathrm{~g} \mathrm{~L}^{-116,21,36,39}$ has been found optimum, which is higher than in the present study $\left(75 \mathrm{~g} \mathrm{~L}^{-1}\right)$. Variation in optimum leaching conditions is substantial in previous publications, and is 
partially a consequence of the differences in the PCB materials used, and also different pretreatment procedures that have been applied.

\section{Chemical Consumption in Leaching and Electrowinning}

Copper, sulfuric acid, and hydrogen peroxide concentrations during leaching are shown in Fig. 3a. The change of acid concentration was minor in the leaching, with a decrease by only $1.7 \%$, which indicates good reusability of the acid. However, hydrogen peroxide concentration decreased rapidly in $45 \mathrm{~min}$ to $4.4 \%$ from the initial concentration and eventually decomposed totally during $90 \mathrm{~min}$. Compared to the leaching of minerals, ${ }^{43}$ the decomposition rate of hydrogen peroxide is faster. When citrate and hydrogen peroxide have been used as leaching agents for PCBs, only $10 \%$ of the hydrogen peroxide has been decomposed below $40^{\circ} \mathrm{C},{ }^{26}$ while in this study, the decomposition was complete at room temperature. Leaching rates of copper decrease over the time, which can be seen from Fig. 5a. Concentrations of other metals in leaching and electrowinning are shown in S.VIII and S.IX in SI.

Copper concentrations decreased linearly during electrowinning, which can be seen from Fig. $3 \mathrm{~b}$. The sulfuric acid concentration increased slowly during the electrowinning and, at the end of the electrowinning, reaches the initial concentration used in the leaching. The obtained copper product had a high purity of over $99.94 \%$, with aluminum $(0.004$ wt.\%), iron (0.001 wt.\%), lead (0.03 wt.\%), and palladium (0.02 wt.\%) as the impurities.

\section{Reusability of Leachate}

Reusability of the leachate was studied by performing five consecutive leaching and electrowinning steps with the re-circulated leachate and pristine PCB material in each step. Copper leaching and electrowinning efficiency were high in each cycle, as can be seen from Fig. 4 a. In cycle $2,15 \mathrm{~mL}$ of fresh $3.5 \mathrm{~mol} \mathrm{~L}^{-1}$ sulfuric acid was added to the leachate before electrowinning due to the higher loss of leachate in filtration. Changes in sulfuric acid concentration remained low, below $5 \%$ in each step, while hydrogen peroxide decomposed in each leaching cycle. The leachate behaved similarly as in the chemical consumption experiments and the addition of hydrogen peroxide in $3.5 \mathrm{~mol} \mathrm{~L}^{-1}$ in sulfuric acid can enable recirculation of the leachate.

In the electrowinning of copper, the cell potential was 2.4-2.5 $\mathrm{V}$ in each cycle with the time of 83 111 min reaching recovery rates of 92.2-96.0\%. Copper purity remained high, over $99.9 \%$ in each of the 5 cycles, as can be seen from Fig. $4 \mathrm{~b}$. Impurities, including lead and palladium, were found in trace concentrations in the recovered copper fraction. As can be seen from Fig. 4c, concentrations of other metals are increased in the leachate during the 5 recirculation cycles. However, the purity of the copper product remained similar in the 5 cycles. Due to increases of base metal concentrations in the leachate, separation of aluminum and iron can be carried out effectively from the sulfuric acid solution, e.g., with diffusion dialysis ${ }^{44}$, which could therefore enable further recirculation of the leachate. Additionally, the morphology of the copper deposit can be affected by the impurities present in the leachate, and should be studied along with removal of impurities.

The process diagram for the copper recovery is presented in Fig. 5. Pretreated PCBs were leached with $3.5 \mathrm{~mol} \mathrm{~L}^{-1}$ sulfuric acid and 6 vol. \% hydrogen peroxide with a pulp density of $75 \mathrm{~g} \mathrm{~L}^{-1}$ followed by filtration. The copper was recovered with high recovery and purity from the leachate using electrowinning. In the recirculation of the leachate, the quantity of concentrated sulfuric acid was $29.5 \mathrm{~mL}$ in the fresh leachate, and $7.4 \mathrm{~mL}$ of concentrated (a)

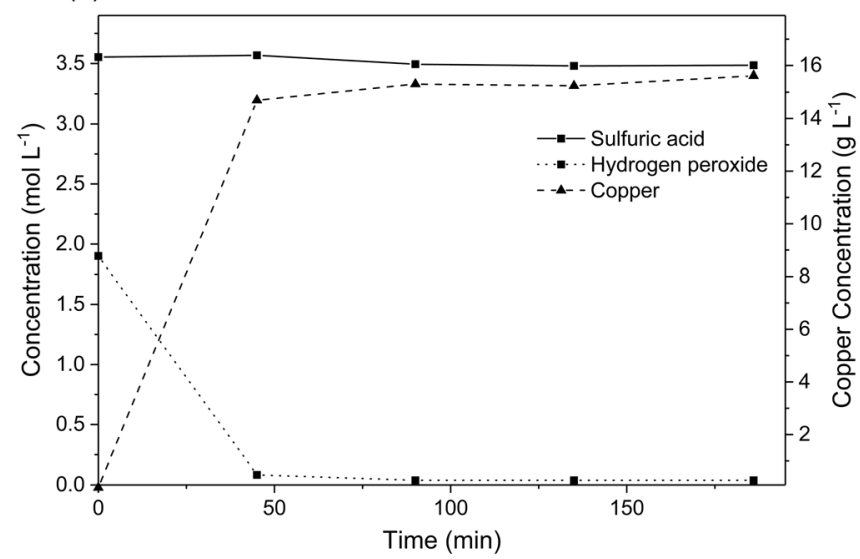

(b)

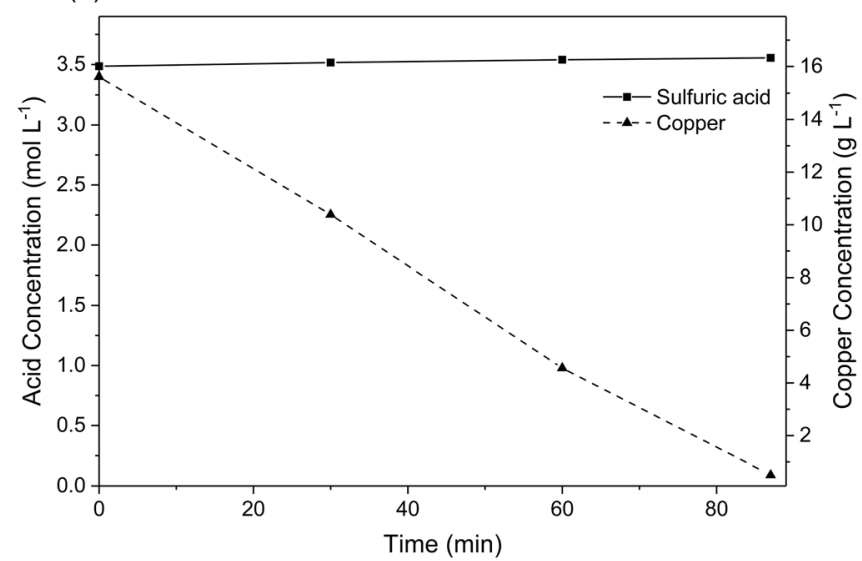

Fig. 3. (a) Concentrations of copper, hydrogen peroxide, and sulfuric acid versus leaching time, (b) concentrations of copper and sulfuric acid versus electrowinning time at $0.04 \mathrm{~A} \mathrm{~cm}^{-2}$ current density $(n=4)$. 
(a)

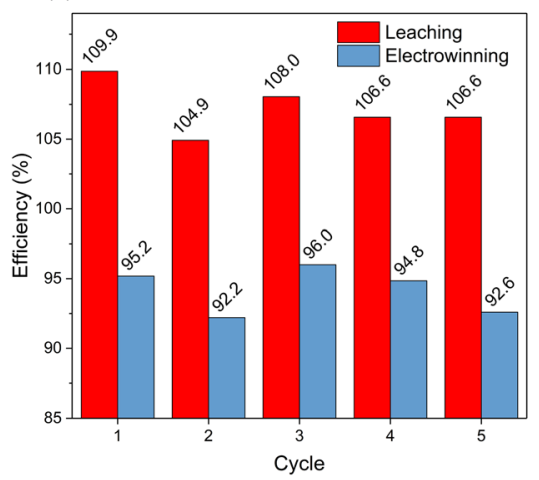

(b)

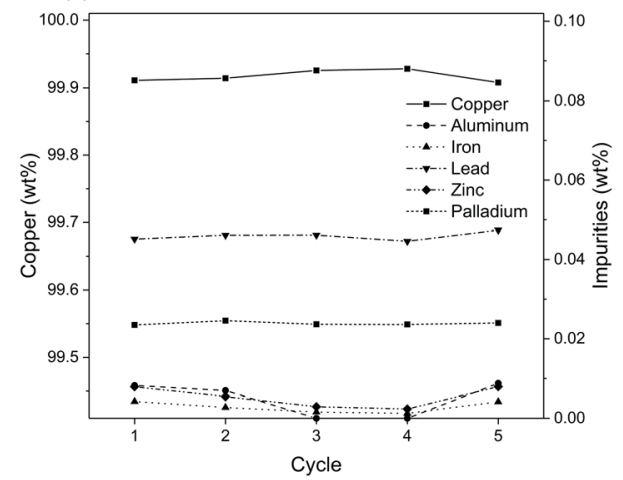

(c)

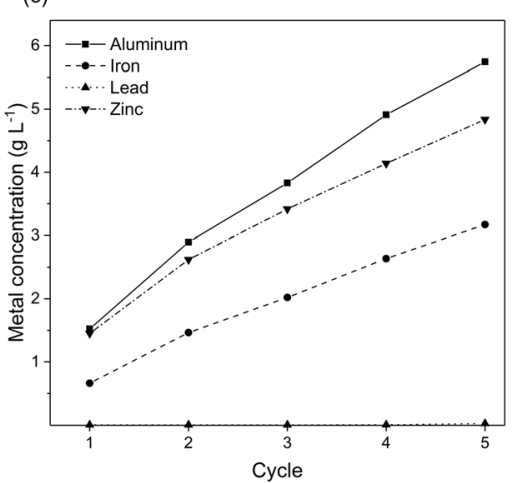

Fig. 4. (a) Copper yields (\%) in leaching and electrowinning, (b) concentration (wt.\%) of copper and impurities in the recovered copper product, and $(\mathrm{c})$ concentration $\left(\mathrm{g} \mathrm{L}^{-1}\right)$ of metals in the leachate in cycles $1-5$.

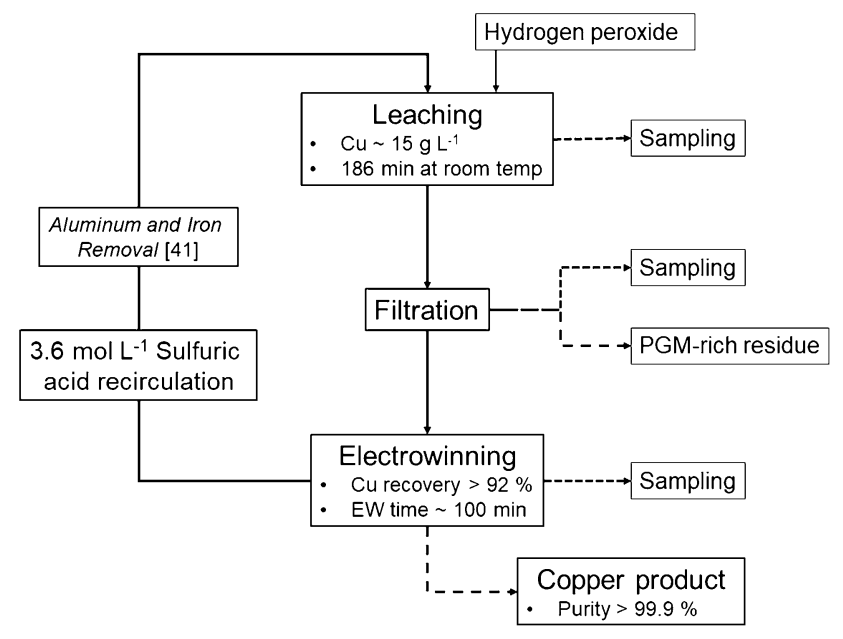

Fig. 5. The studied recirculation process with keypoints and including optional aluminum and iron removal.

acid was added in cycles $2-5$ to adjust to the optimum concentration of the leachate. Therefore, the chemical consumption can be reduced by $60 \%$ with the 5-cycle recirculation instead of the use of fresh acid in each recovery cycle. The copper leaching step leads to a solid residue with a higher precious metal content, which can then be recovered in subsequent processing steps. The leachate can be recycled after electrowinning, and hence the chemical consumption can be decreased significantly in the entire process. The solid residue can be leached by, e.g., aqua regia followed by precious metal recovery with either conventional methods or more novel approaches, such as 3D-printed scavengers. ${ }^{45,46}$ Thiourea leaching has also beenwidely studied for gold and silver recovery from electronic waste. $^{47,48}$

\section{CONCLUSION}

This study achieved an effective recovery process for copper from pretreated PCBs, with optimized leaching steps and electrowinning. Optimization of copper recovery included RSM optimization of leaching conditions using sulfuric acid and hydrogen peroxide leaching, and estimation of the chemical consumption in each step. Two optimum conditions, with over $96 \%$ efficiency, were found and tested experimentally for the leaching of copper, with $3.5 \mathrm{~mol} \mathrm{~L} \mathrm{~L}^{-1}$ sulfuric acid and 6 vol.\% hydrogen peroxide using $75 \mathrm{~g} \mathrm{~L}^{-1}$ pulp density, while differences between leaching conditions were leaching time and temperature $\left(186 \mathrm{~min}\right.$ at $20^{\circ} \mathrm{C}$ versus $60 \mathrm{~min}$ at $60^{\circ} \mathrm{C}$ ). Hydrogen peroxide was decomposed in 90 min during the leaching, while only minor changes were observed in the sulfuric acid concentration in each step. Copper was recovered directly from the leachate with over $92 \%$ recovery using electrowinning, while product purity were over $99.9 \%$. Recovery rates and the purity of copper remained high during 5 consecutive recirculation cycles, with the addition of hydrogen peroxide and a minor addition of concentrated sulfuric acid. In the 5 cycles, sulfuric acid consumption was reduced by up to $60 \%$ compared to the use of fresh leachate for this recovery process. The proposed process could further accelerate the utilization of secondary resources such as waste PCBs.

\section{ACKNOWLEDGEMENTS}

The authors wish to thank the Finnish Innovation Fund (SITRA) and the Department of Chemistry at the University of Jyväskylä for financial support during this work. Rantasalmen SCEL Ltd. and Elker Ltd. are gratefully acknowledged for the provision of the PCB material.

\section{FUNDING}

Open access funding provided by University of Jyväskylä (JYU).

\section{CONFLICT OF INTEREST}

On behalf of all the authors, the corresponding author states that there is no conflict of interest. 


\section{OPEN ACCESS}

This article is licensed under a Creative Commons Attribution 4.0 International License, which permits use, sharing, adaptation, distribution and reproduction in any medium or format, as long as you give appropriate credit to the original author(s) and the source, provide a link to the Creative Commons licence, and indicate if changes were made. The images or other third party material in this article are included in the article's Creative Commons licence, unless indicated otherwise in a credit line to the material. If material is not included in the article's Creative Commons licence and your intended use is not permitted by statutory regulation or exceeds the permitted use, you will need to obtain permission directly from the copyright holder. To view a copy of this licence, visit http://creativecommons.org/licenses/by/4.0/.

\section{ELECTRONIC SUPPLEMENTARY MATERIAL}

The online version of this article (https://doi.org/ 10.1007/s11837-020-04510-z) contains supplementary material, which is available to authorized users.

\section{REFERENCES}

1. C.P. Baldé, V. Forti, V. Gray, R. Kuehr, and P. Stegmann, The Global E-Waste Monitor - 2017, United Nations University (UNU), International Telecommunication Union (ITU) \& International Solid Waste Association (ISWA), Bonn/Geneva/Vienna (Bonn/Geneca/Vienna, 2017).

2. European Parliament and Council, Directive 2012 / 19/EU of the European Parliament and of the Council of 4 July 2012 on Waste Electrical and Electronic Equipment (WEEE) (The European Union, 2012).

3. E. Union, Directive 2011/65/EU of the European Parliament and of the Council of 8 June 2011 on the Restriction of the Use of Certain Hazardous Substances in Electrical and Electronic Equipment (The European Union, 2011).

4. J. Cui and L. Zhang, J. Hazard. Mater. 158, 228 (2008).

5. S. Zhang and E. Forssberg, Resour. Conserv. Recycl. 21, 247 (1997).

6. J. Li, H. Lu, J. Guo, Z. Xu, and Y. Zhou, Environ. Sci. Technol. 41, 1995 (2007).

7. J. Li, Y. Jiang, and Z. Xu, J. Clean. Prod. 141, 1316 (2017).

8. T. Havlik, D. Orac, M. Petranikova, A. Miskufova, F. Kukurugya, and Z. Takacova, J. Hazard. Mater. 183, 866 (2010).

9. E. Ventura, A. Futuro, S.C. Pinho, M.F. Almeida, and J.M. Dias, J. Environ. Manag. 223, 297 (2018).

10. U. Jadhav and H. Hocheng, Sci. Rep. 5, 14574 (2015).

11. H.R. Verma, K.K. Singh, and T.R. Mankhand, J. Clean. Prod. 142, 1721 (2017).

12. H. Lee and B. Mishra, Miner. Eng. 123, 1 (2018).

13. R. Torres and G.T. Lapidus, Waste Manag. 57, 131 (2016).

14. H. Lee, M. Bae, E. Lee, and B. Mishra, JOM 71, 2360 (2019).

15. U. Javed, R. Farooq, F. Shehzad, and Z. Khan, J. Environ. Manag. 211, 22 (2018).

16. H. Yang, J. Liu, and J. Yang, J. Hazard. Mater. 187, 393 (2011).
17. D. Dutta, R. Panda, A. Kumari, S. Goel, and M.K. Jha, Sustain. Mater. Technol. 17, e00066 (2018).

18. A. Barnwal and N. Dhawan, Sustain. Mater. Technol. 25, e00164 (2020).

19. P.P. Sheng and T.H. Etsell, Waste Manag. Res. 25, 380 (2007).

20. N. Naseri Joda and F. Rashchi, Sep. Purif. Technol. 92, 36 (2012).

21. H. Lee and B. Mishra, Miner. Process. Extr. Metall. Rev. 41, $153(2020)$.

22. E. Tanısalı, M. Özer, and F. Burat, Miner. Process. Extr. Metall. Rev. 00, 1 (2020).

23. Y. Hong and M. Valix, J. Clean. Prod. 65, 465 (2014).

24. A. Işıldar, J. van de Vossenberg, E.R. Rene, E.D. van Hullebusch, and P.N.L. Lens, Waste Manag. 57, 149 (2016).

25. E. Karwowska, D. Andrzejewska-Morzuch, M. Lebkowska, A. Tabernacka, M. Wojtkowska, A. Telepko, and A. Konarzewska, J. Hazard. Mater. 264, 203 (2014).

26. R. Torres, B. Segura-Bailón, and G.T. Lapidus, Waste Manag. 71, 420 (2018).

27. J.G. Yang, Y.T. Wu, and J. Li, Hydrometallurgy 121-124, 1 (2012).

28. M. Sethurajan and E.D. van Hullebusch, Metals (Basel) 9, 1 (2019).

29. C.J. Oh, S.O. Lee, H.S. Yang, T.J. Ha, and M.J. Kim, J. Air Waste Manag. Assoc. 53, 897 (2003).

30. I. Birloaga, V. Coman, B. Kopacek, and F. Vegliò, Waste Manag. 34, 2581 (2014).

31. B. Mizero, T. Musongo, E.R. Rene, F. Battes, and P.N.L. Lens, Process Saf. Environ. Prot. 120, 14 (2018).

32. H.M. Veit, A.M. Bernardes, J.Z. Ferreira, J.A.S. Tenório, and C.F. Malfatti, J. Hazard. Mater. 137, 1704 (2006).

33. J. Fox, J. Stat. Softw. 14, 1 (2005).

34. U. Groemping, RcmdrPlugin.DoE: R commander plugin for (industrial) Design of experiments, version 0.12-3. https:// cran.r-project.org/web/packages/RcmdrPlugin.DoE/index. html (2014).

35. R Development Core Team 3.0.1., R Found. Stat. Comput. 2. https://www.R-project.org (2013).

36. I. Birloaga, I. De Michelis, F. Ferella, M. Buzatu, and F. Vegliò, Waste Manag. 33, 935 (2013).

37. W. Haynes and D. Lide, CRC Handbook of Chemistry and Physics: A Ready-Reference Book of Chemical and Physical Data, 91st ed. (Boca Raton: CRC, 2010).

38. Á. Ruiz-Sánchez and G.T. Lapidus, Hydrometallurgy 169, 192 (2017).

39. A. Tuncuk, Waste Manag. 95, 636 (2019).

40. M.A. Bezerra, R.E. Santelli, E.P. Oliveira, L.S. Villar, and L.A. Escaleira, Talanta 76, 965 (2008).

41. J.N. Miller and J.C. Miller, Statistics and Chemometrics for Analytical Chemistry, 6th ed. (Pearson: Harlow, 2010).

42. R.H. Myers, D.C. Montgomery, and C.M. Anderson-Cook, Response Surface Methodology: Process and Product Optimization Using Designed Experiments, 4th ed. (New York: Wiley, 2016), pp. 13-66.

43. V. Mahajan, M. Misra, K. Zhong, and M.C. Fuerstenau, Miner. Eng. 20, 670 (2007).

44. W. Li, Y. Zhang, J. Huang, X. Zhu, and Y. Wang, Sep. Purif. Technol. 96, 44 (2012).

45. E. Lahtinen, L. Kivijärvi, R. Tatikonda, A. Väisänen, K. Rissanen, and M. Haukka, ACS Omega 2, 7299 (2017).

46. E. Lahtinen, M.M. Hänninen, K. Kinnunen, H.M. Tuononen, A. Väisänen, K. Rissanen, and M. Haukka, Adv. Sustain. Syst. 2, 1800048 (2018).

47. A. Batnasan, K. Haga, and A. Shibayama, JOM 70, 124 (2018).

48. H. Lee, E. Molstad, and B. Mishra, JOM 70, 1616 (2018).

Publisher's Note Springer Nature remains neutral with regard to jurisdictional claims in published maps and institutional affiliations. 